\title{
Games, Learning and Engagement: What Teachers might learn from Games Designers
}

\author{
Simon Grey* \\ University of Hull \\ *Corresponding Author: s.grey@hull.ac.uk
}

Keywords: Engagement, Motivation, Game Design

\begin{abstract}
This paper explores the role of games in learning. Beginning with some carefully selected definitions of games, comparisons are drawn between the fields of games design and of learning and teaching, highlighting a parallel between games as designed experiences, and teaching as designed learning experiences. Games are seen as being highly engaging, which has led to a rise in the fields of Game Based Learning and Gamification. Ultimately when designing games, game based learning, gamified experiences or learning experiences engagement is a key factor. This leads to the study of human psychology and motivation including concepts of extrinsic versus intrinsic motivation (Pink, 2011), self-determination theory (Rigby \& Ryan, 2010) and flow (Csikszentmihalyi, 1990).
\end{abstract}

\section{Games \& Learning}

There are many definitions of games, making clear distinctions between games and toys, which facilitate more open- ended play. Schell (2014) writes of games as enablers of designed experiences, taking care to point out that games are not experiences themselves. This concept can be related to learning and teaching, and teaching artefacts as designed learning experiences. McGonigal (2012) proposes four properties that define games: they are that a game should have a goal, a system of rules, a feedback system and voluntary participation. Using this definition many other activities, including higher education itself could easily fall into the classification of a game.

Games have also featured as part of learning both through game based learning and gamification of education. Game Based Learning is about learning from playing games (Squire, 2011). "Where in the World is Carmen Sandiego?" is an early example of a game made specifically for educational purpose (anon. 1983). Carmen Sandiego became a franchise producing a series of games, TV shows and films around the central character. Some commercial games have also been identified as being particularly effective at supporting learning include Sid Meier's "Pirates" (Squire, 2011) and more recently the historical "Assassin's Creed" series (Osborg, 2014).

Game based learning is not without its criticisms. Whilst citing the main motivation of games in education as being to increase engagement by making learning fun, and to encourage active learning through doing, Kirriemuir and McFarlane (2004) identify that, among other things games designed for education often suffer from poor design. Additionally, Kirriemuir and McFarlane write of a further criticism of games in learning is that the time spent playing engaged in edutainment is significant, and suggest that this time could be better spent on other activities.

Gamification is a relatively new term that first appeared on the Gartner hype cycle for 
emerging technologies in 2011 (Fenn \& LeHong, 2011). Deterding et al. (2011) propose the definition of gamification as "the use of game design elements in a non-game context". Examples of gamification include customer loyalty and rewards schemes. However, designing an engaging game, or engaging gamified learning material is not as simple as adding points, badges and leaderboards. Kapp (2012) warns that gamification often represents a layer of extrinsic motivators. Extrinsic motivators are rewards awarded for desirable behaviour, or punishments for undesirable behaviour. Extrinsic motivators are separate and distinct from a particular task as opposed to intrinsic motivation that comes from the task itself. For example money is often used as a reward for work, and marks are awarded for a good performance in an assessment. Pink (2011) presents evidence identifying the negative effects of extrinsic motivators, which include diminishing performance, crushing creativity, fostering short term things and encouraging cheating.

This section has included information about different aspects of games that can be applied to learning, from create games that teach in game based learning to applying game mechanics to teaching, without an explicitly defined game in gamification. The distinction between extrinsic and intrinsic motivation has also been touched upon. The dangers of extrinsic motivators exist for both game based learning and gamified experiences. The desire to win a game is an extrinsic motivator, that unless carefully designed may be separate to the task in hand. In the next section a game design methodology will be examined that may offer a clue towards avoiding undesirable emergent behaviour as a result of added extrinsic motivators.

\section{Game Design Methodology}

Often the desire to incorporate elements of games into learning is centred on making learning fun, however there are arguments that learning is fun. For example, it is common to hear a self-motivated learner say that they are "playing around" with a new idea that drives their learning. Game designer Chris Crawford makes the claim that "the fundamental motivation for all game playing is to learn"
(Crawford, 2011). Koster (2010) makes the point that once a player has learnt all there is to learn about a game then it stops being fun, and claims that "Fun is just another word for learning". Koster also notes that games players have developed their own terminology for understanding, adopting the term "grok" when then have developed a good understanding of a game.

Much research into game design includes recognition that a game represents a designed emotional experience. Lazzaro (2004) identifies four keys to fun: hard fun, easy fun, serious fun and people fun. Hard fun is the feeling of joy after have achieved something that is very difficult. Easy fun stems from natural curiosity and discovery. Serious fun is linked to excitement and people fun relates to social connections and relatedness. In contract Hunicke et al. (2004) identify eight kinds of fun. Most notable, in the context of learning and teaching, are challenge and discovery. Dillon (2010) goes one step beyond emotions by linking six emotions to eleven primal instincts. When designing a game the designer make hundreds, sometimes thousands of decisions (Schell, 2014). Just as poorly constructed game based learning or gamification can lead to unexpected and undesirable outcomes, games designers have begun to try to formalise what fun is, and develop methodologies for thinking about game design. One question of interest is: what drives us to play games?

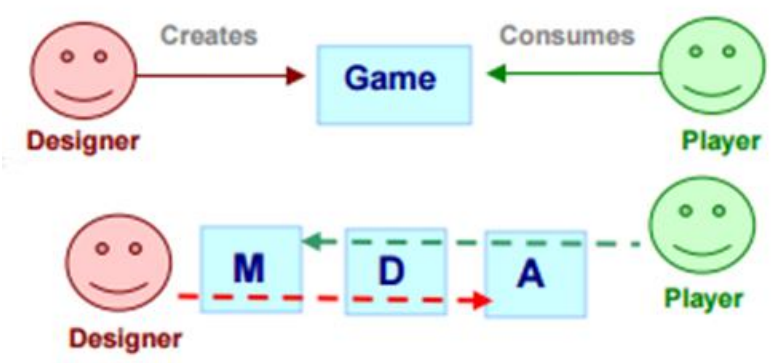

Figure 1 The Mechanics-DynamicsAesthetics design model (adapted from Hunicke et al 2004)

The methodology presented in Figure 1 is the Mechanics-Dynamics-Aesthetics model for game design (Hunicke et al, 2004). This model recognises the contrasting positions of game designer, who creates the rules or mechanics 
of a game, and game player who the aesthetic experience of the game. In between, dynamics are the emergent behaviour that arises as a result of the mechanics. In the example of poker, dynamics include bluffing, and bullying a player with fewer chips. These strategies are not part of the mechanics of poker, but they emerge as a result of the mechanics.

Dynamics can also result in surprising, and often undesirable behaviours. In the field of academia the mechanics might be that students are expected to register their attendance in laboratories or face some remedial action. The desired dynamics are that the students attend and therefore engage, and complete their work. The student has avoided a punishment for non-attendance but their engagement, or not, is not adequately recorded. In this example avoiding punishment is an extrinsic motivator. The potential emergent dynamics demonstrates the negative effect of extrinsic motivators.

\section{Motivation \& Psychology}

The goal to create an engaging experience is common to both games and learning. If a game is not engaging then it will not be played. What makes an engaging experience is a question of psychology and motivation to play.

One aspect of psychology that is coveted by games designers is the concept of Flow. Flow is a state of total engagement and concentration (Csikszentmihalyi, 1990). This concept of the optimum experience, often referred to as being "in the zone" is a goal of many game designers. In fact, games have been created in which this concept is the central focus (anon, 2016). To produce such an experience a player (or learner) requires a challenge that is well suited to their level of skill, as well as a system that can give immediate meaningful feedback. Meaningful feedback has long been recognised as an effective tool to aid learning. The requirement of a challenge that is suited to an individual's level of skill represents an argument in favour of personalised learning.

Self-determination theory (Ryan \& Deci, 2000) states that people are motivated by competence, autonomy and relatedness. This idea can be linked to Maslow's hierarchy
(Maslow, 1943), which shows that once basic needs are satisfied we are motivated by higher level motivators. Ryan and Deci also offer an analogue measure of motivation called organismic integration theory. Organismic integration theory (OIT) describes an individual's actions on a scale of selfdeterminism, and includes a scale of extrinsic and intrinsic motivations. This recognises that people may be motivated by a task if they believe it might lead to an extrinsic reward.

The concepts of competence, autonomy and relatedness are used in game design constantly. Autonomy can be provided by allowing players a choice over what their character looks like, and by a genre of games, known as sand box games, which are nonlinear in nature and provide players with huge amounts of choice in what they do. Competence is an important aspect of games in general, and of those games that attempt to give a "hard fun" experience. As games become more social experiences, relatedness becomes an increasingly important factor in games, but it has been present ever since a game introduced a high scores table.

\section{Summary}

It seems that teachers often covet the power games have to engage players, and wonder how this power might be applied to learning material. This has given rise to the fields of game based learning and gamification. Both game based learning and gamification can have their drawbacks, but by considering games design it becomes clear that in the design of both games and teaching there is a focus on engagement. Not all games are successful in engaging their players. Games that are not engaging are not played, which one could argue makes that game a failure. The same could be said of teaching. If students do not engage with teaching that teaching is a failure.

Game based learning and gamification are sometimes seen as gimmicks, but by looking at the ways that games designers attempt to engage their players it is possible to find a lot of concepts that are shared by teaching. Given that timely and meaningful feedback, appropriate challenges and allowing autonomy are common themes in both disciplines 
Games, Learning and Engagement: What Teachers might learn from Games Designers

perhaps engaging games and effective teaching are closer than they seem.

\section{References}

anon. (2014) Where in the World is Carmen Sandiego? Retrieved 06/03/2014 from http://www.carmensandiego.com/.

anon. (2016) that game company. Retrieved 25/09/2016 from http://thatgamecompany.com/games/

Crawford, C. (2011). The Art of Computer Game Design. New York, McGraw Hill Osborne Media.

Csikszentmihalyi, M. (1990). Flow: The Psychology of Optimal Experience. New York, Harper Perrenial.

Deterding, S., Dixon, D., Khaled, R., \& Nacke, L. (2011) From game design elements to gamefulness: defining gamification, In Proceedings of the 15th International Academic MindTrek Conference: Envisioning Future Media Environments, September 2830, 2011, Tampere, Finland, ACM, pp. 9-15. doi: 10.1145/2181037.2181040

Dillon, R. (2010) On the Way to Fun: an Emotion Based Approach to Successful Game Design, AKPeters

Fenn, J. \& LeHong, H. (2011) Hype Cycle for Emerging Technologies, Gartner Group, Stamford, CT, July 2011

Hunicke R., LeBanc M. \& Zubek R. (2004) MDA: a Formal Approach to Game Design and Research In Proc. $19^{\text {th }}$ National Conference on Artificial Intelligence, San Jose', CA

Kapp, K. (2012). The Gamification of Learning and Instruction: Game-based Methods and Strategies for Training and Education. San Francisco, Pfeiffer.

Kirriemuir, J., \& McFarlane, A. (2004). Literature review in games and learning: $A$
Report for NESTA Futurelab. http://www.futurelab.org.uk/resources/docume nts/lit reviews/Games Review.pdf [last access: $27 / 08 / 2007]$

Koster, R. (2010). A Theory of Fun for Game Design, Paraglyph Press.

Lazzaro, N. (2004). Why We Play Games: Four Keys to More Emotion Without Story. Oakland, XEODesign, Inc.

Maslow, A.H. (1943) A Theory of Human Motivation Psychological Review. 50 (4): 37496. doi: $10.1037 / \mathrm{h} 0054346$

McGonigal, J. (2012). Reality is Broken: Why Games Make Us Better and How They Can Change the World. London, Vintage.

Osborg, M (2004) The Assassin's Creed Curriculum: Can Video Games Teach Us History? Retrieved 25/09/2016 from http://www.theverge.com/2014/9/18/6132933/t he-assassins-creed-curriculum-can-videogames-teach-us-history

Pink, D. (2011). Drive: The Surprising Truth About What Motivates Us. New York, Canongate.

Rigby, S. \& R. Ryan (2010). Glued to Games: How Video Games Draw Us in and Hold Us Spellbound. Santa Barbara, Praeger.

Ryan, R., \& Deci, E.L. (2000). SelfDetermination Theory and the Facilitation of Intrinsic Motivation, Social Development, and Well-Being. American Psychologist, 55, 68-78. doi: 10.1037//0003-066X.55.1.68

Schell, J. (2014) The art of game design: $A$ Book of Lenses, 2nd edition. Hoboken: CRC Press.

Squire, K. (2011). Video Games and Learning: Teaching and Participatory Culture in the Digital Age. New York, Teachers College Press. 